\title{
eCity: Virtual City Environment for Engineering Problem Based Learning
}

\author{
P. Lahuerta*, A. Cháfer** \\ *Department of Inorganic Chemistry, **Department of Chemical Engineering \\ University of Valencia, Dr. Moliner 50, 46100 Burjassot-Valencia, Spain
}

\begin{abstract}
The main objective of the eCITY project is to design, develop and validate a pedagogical methodology, supported by an online, collaborative, city-development simulation engine (Simcity like) that stimulates the integration and continuous exploitation of Problem-Based Learning (PBL) in engineering and science schools but, at the same time, fostering the interest for these orientations in secondary school students.
\end{abstract}

Keywords: eCITY project; city-development simulation engine; Problem-Based Learning; secondary school students.

\section{Introduction}

The difficulty that secondary education students have with Mathematics and other Science topics is a widespread problem in Europe as stated by several international comparative studies like PISA or TIMMS. This prevents these students to follow a technical academic path like Engineering or Sciences. This generation is the "netgeneration" or "digital natives": they quickly absorb information in shorter chunks, they expect instant responses and feedback and they want to be active in their learning.

Problem-based learning (PBL) is a learner-centered educational pedagogy in which students develop their ability to go through a problem solving process, usually based on real-life situations. Engineering is one of the areas where PBL is a valid learning alternative/complement to the traditional learning methods. Several authors ( Tree (2007); Lacuesta (2009) ; Felder et al (2000) ; Kolmos et al. (2004) ; Woods (1994) Kolmos (2011)) have reported benefits for engineering students considerable improvements in critical, lateral and creative thinking, problem solving skills, group collaboration and communication skills.

In a convergent path, games and simulations can be instantiated for learning as they involve mental and physical stimulation and develop practical skills as they force the player to decide, choose, to define priorities, solve problems, etc. One of the main reasons for the increased research and development interest in computer games for learning purposes is that those games are believed to have the potential to support innovative constructivist-inspired models of learning, such as learning-by-doing, exploratory learning, situate learning and learning through participation in communities of practice (Facer (2003); Shaffer et al. (2004)). It, thus, seems that computer games offer a powerful new medium to support learning in the information age (Kirriemuir et al. (2004)). This assertion holds especially true for educational online games, which, relying on the inherent capabilities for communication, interaction, and resource sharing provided by the Internet and the Web. Can offer increased opportunities for collaborative learning an knowledge construction through social interaction. Papastergiou (2008) in a review about the use of computer games for educational proposes, conclude that educational online games should constitute engaging virtual environments that offer students authentic, goaloriented, challenging, exploratory, experiential, collaborative problem-solving learning 
experiences that reflect real-life situations that scientists or professional of the respective field encounter in their everyday practice. This overviewed study show that student's response to the educational online games were very positive. Students clearly enjoyed the games and found them interesting, motivational, immersive, beneficial and worthwhile. They felt that such games offer a realistic and useful way to learn.

\section{Methods}

The main objective of the eCITY project is to design, develop and validate a pedagogical methodology, supported by an online, collaborative, city-development simulation engine (Simcity like) that stimulates the integration and continuous exploitation of Problem Based Learning in engineering schools but at the same time, fostering the interest in Engineering in secondary school students.

ECity's PBL virtual learning environment (VLE) is expected to be a general and stimulating context especially due to the nature and complexity of the range of problems that will be available in the virtual city. The platform will also promote a sense of belonging to a community, peer support and an additional rewarding system that includes reputation points for problem solving, allowing the establishment of rankings (promoting an healthy competition).

The platform is integrated in a clear pedagogical methodology, PBL-oriented, to ensure that the upmost relevance is given to the learning process.

New problems or challenges can be fed into the platform as homework, teamwork, curricular activities, extra-curricular competition, big or small projects, etc.

PBL can be incorporated within the existing structures with little disruption as it can be implemented in a variety of forms. Therefore it is not necessary to change the curricular organization problems can be formatted to different time and work schemes.

Many PBL courses and activities still rely mainly on traditional face-to-face activities. Nevertheless it has been suggested that Virtual Learning Environments (VLE) enhance the PBL experience and effectiveness (Tree (2007); Lacuesta (2009); Felder et al (2000) ; Kolmos et al. (2004) ; Woods (1994) Kolmos (2011)).

A VLE is an online (frequently Web 2.0 based) education platform that models conventional real-world education by integrating a set of equivalent virtual concepts for contents, lectures, tests, assignments, classes, classrooms and other academic resources. These tools have the potential to increase the communication between a larger number of educational actors (VLEs4VET project (2007); Pot (2004); Miao et al. (1999)). The definition of VLE encompasses a large number of different types of learning platforms:

In some cases to follow the games, the academic knowledge is used as a tool to achieve goals. This means that to play the user will need to have some previous knowledge and, in addition, such knowledge must be expanded to move forward in the game itself. There is therefore a kind of binomial fun / knowledge. Knowledge becomes a necessity to succeed in the game, which will motivate the learning of it by students.

However in some cases it is not necessary to have a certain initial knowledge, just enough student's curiosity or intuition, and the game itself would be enough to provide or promote additional knowledge. 


\section{Results}

The simulation engine is now developed and students can access to it through the following web: http://ecity-project.eu/es/game/

Here is a list of the problems selected by for implementation in eCity platform with a brief description of the context, goals and expected results of each problem.

\section{Cloud Infrastructure for Whatsapp Servers}

Facebook wants to extend the whatsapp functionalities in our city. The company wants to improve their functionalities trying to provide a good response-time taking into account the number of present and future clients and also the increase in service needs. They need to decide how many servers to deploy, where these servers (memory, computing) are going to be located, the links and capacity among the servers, the energy sources, the needs for redundant systems, backup issues, wifi connections, wireless communications, antennas distribution, etc. Previous knowledge of Physics and Mathematics will be required

\section{Purification of a natural gas field}

The city needs a supply of energy from different sources. The recent prospections in the area have found a natural gas deposit that might provide enough energy to cover up to $20 \%$ of the city regular consumption. The analysis reflects a measurable content of pollutants-containing compounds, mainly $\mathrm{SH}_{2}$ and $\mathrm{CO}_{2}$, that makes the natural gas unsuitable in the present conditions. Gas purification involves the removal of the impurities from the gas streams. Information about the primary operation of gas purification processes will be provided to the students. This problem will include the treatment of the separated residues and the possible transformation in products with commercial application. Previews knowledge of basic chemistry will be required.

\section{Creating an earthquake-resistant city}

The city is located near a fault zone. The player will select the correct place by evaluating various factors like the expected earthquake gratitude, history of earthquakes in the area, soil types and combinations, nearness to the fault zone and decide on the type of construction, materials to be used for construction, maybe even the type of concrete to be used, cost of construction, number of floors etc. At the end of the given time there will be an earthquake simulation to show success of the player.

The aim is to provide the correct balance between an economic and social development of a city and the life guarantee of its inhabitants. The background knowledge depends on the target players of the game. If it is being played for secondary school students, the teacher will assign simpler factors.

\section{MyMVNO's Access Network deployment}

MyMVNO is a Mobile Virtual Network Operator company that has experienced a large increase of customers in recent years. Being a virtual operator, the company lacks any access infrastructure. In other words, the company does not have its own Access Network (AN) and it has to pay to other providers for using their infrastructure. Therefore, MYMVNO intends to deploy its own infrastructure and it wants to perform some simulations. The objective of the simulations is to verify that the company can deploy its 
own infrastructure while maintaining service quality (i.e. increasing operator's revenue) and reduce their operation costs. The learning goal of this game is to provide a view of how a mobile network works. This is addressed to engineering students with knowledge in telecommunications (signal, channel access methods, mobile network architecture), Energy, Cost Management Skills and Physics.

\section{Operation of industrial activities.}

The community needs to have an industrial base to generate jobs and provide needed consumer goods. This includes installations of various types of industries, such as bakery, slaughter of animals, paint factory, winery, manufacture of ceramic products, vegetable processing plants, dairies, etc. The student will find the most suitable method to reduce the residues generated by the industry, so that they meet the environmental requirements of the community. At an elementary level of the problem, a list with the nature of the waste generated by the industry as well as the properties and hazards will be provided.

\section{Code-Living City}

The game presents a future city as a living entity that is able to control some of its public services. Particularly, streets are journeyed by automatic buses, taxis and other vehicles that are driven by automatic systems. Students will be required to program these systems, so the vehicles move around the city according to their planned routes to serve the city inhabitants. Students must model these active elements by using programming sentences. This will bring them the opportunity to experiment with programming elements. For example, students will model a bus journeying its route; or will create algorithms to make taxis to offer their services to the inhabitants of the city, etc.

The game can be composed by many stages. The goal of the game is to fulfil the requirements of each stage until all stages are done. As long as the stages are completed, students will learn basic concepts of programming languages oriented to Object-Oriented Programming languages (OOP). So, it is expected that students will be able to learn programming basics while competing against their peers.

\section{Building, setting up and testing a Local Area Network}

The fundamental proposal's goal is the development of a serious allow students to acquire skills and competencies in the informatics sector to be applied in the real world. By playing real-life situations students have to build a Local Network Area (LAN), set it up and test it using specific knowledge inside a simulated and protected work environment. Thank to this proposal the game will consent students to select at least 5 problems where different type, dimension of net subnet, and device have to functioning in a Local Network Area. Furthermore students will have the opportunity to set up new problems by themselves and then try to solve them.

\section{Busses to the University and Beyond}

The problem involves the need to provide bus services to attend university students, and other users: K-12, high school students and public in general. Each one of these users has different timetables and travels. The objective of the problem is to optimize the use of buses, supporting all people with the minimum number of buses and drivers. We want to reduce the carbon footprint also: if not enough buses are provided, the people will use their own cars and the pollution will increase. The game/simulation application will show a particular city with some schools and roads. Students need to decide the routes, the 
number of buses, the timetables, etc. The application will calculate the number of cars needed, the pollution produced, etc.

\section{Energy supply to the city}

The city needs energy supply that can be obtained from different sources, coal, nuclear plant, wind farms or solar energy plants. When selecting a new energy source for the city the student should take into account different aspects: building cost, maintenance cost, sourcing capacity and environmental impact.

Figure 1 show a scenario when most of the city has received electricity supply from different sources.

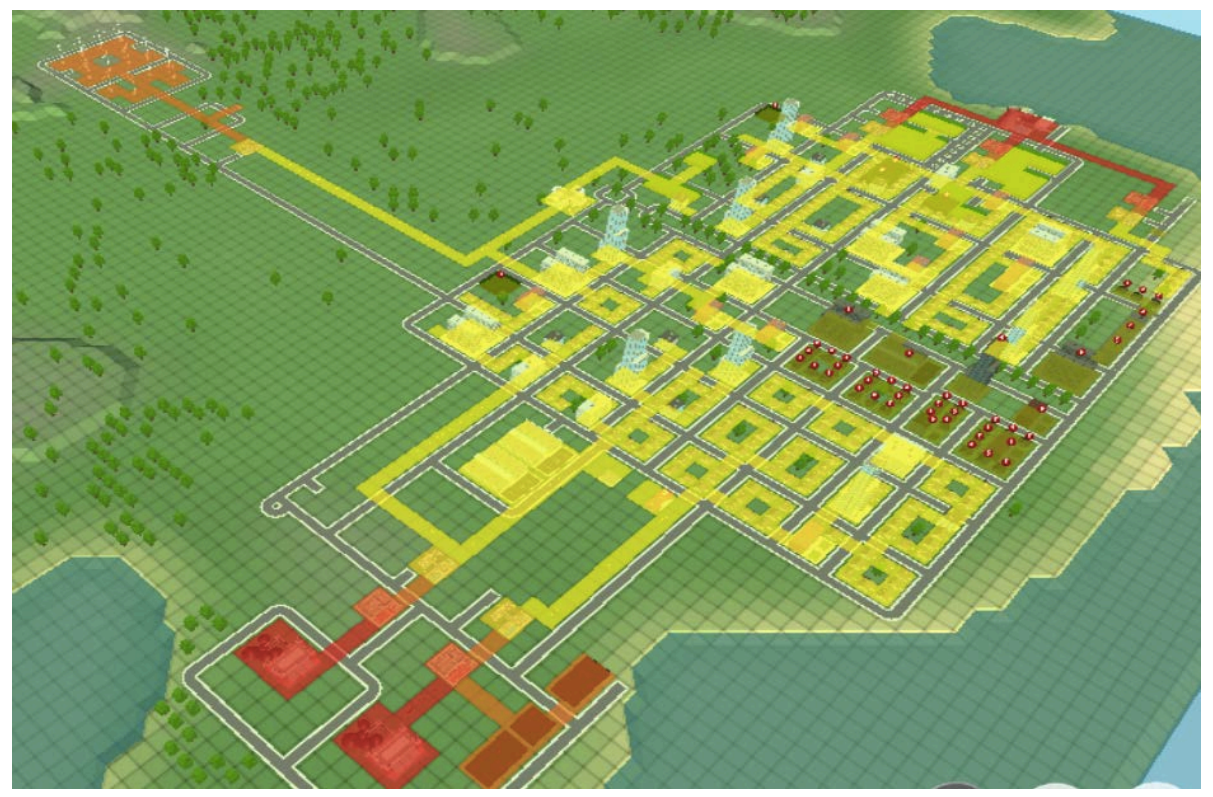

Figure 1. A view of a scenario of the city when most of the buildings has received electricity supply form different sources.

\section{Conclusions}

At this moment, the simulation engine is finished in English and it is being traduced to different languages as Spanish, Italian, Greek, etc.

The project will continue the activity until the end of 2015. Now we are broadcasting the simulator eCity between the Secondary educational community, so that this tool could be apply in their classes the next course. Considering that some of the problems will be also oriented to secondary school students, the participation of schoolteachers in the project will be highly beneficial. 


\section{References}

Facer, K. (2003) Computer games and learning. Last access April 16, 2015, from http://www2.futurelab.org.uk/resources/documents/discussion_papers/Computer_G ames_and_Learning_discpaper.pdf

Felder, A., Woods, R., Stice, M., Rugacia, J., (2000) The future of engineering education ii. Teaching methods that work, Chem. Eng. Educ. 34, vol. no. 1,

Kirriemuir, J. McFarlane, A. (2004) Literature review in games and learning: A report for NESTA Futurelab. Last access April 16, 2015, from https://hal.archives-ouvertes.fr/hal-00190453/document

Kolmos, A. (2011) New trends in engineering education: Mega projects and globalization, Proceedings of the 1st EUCEET Association Conference, Patras, Greece.

Kolmos, A., Gynnild V. and Roxå T. (2004): The Organisational Aspect of Faculty Development, in Anette Kolmos, Ole Vinther, Pernille Andersson, Lauri Malmi and Margrete Fuglem, eds: Faculty Development in Nordic Engineering Education, Aalborg University Press, 2004.

Lacuesta, R. (2009) Active learning through problem based learning methodology in engineering education. Proc. 39th IEEE Int. Conf. Front. Educ. Conf., pp. 530-535.

Miao, Y.; Fleschutz, M. and Zentel, P. (1999) Learning contexts to support communities of practice. Proc. CSCL, pp. 391-397.

Papastergiou, M. (2008), Online computer games as collaborative learning environments: prospects and challenges for tertiary education. J. Educational Technology Systems, 37, 19-38.

Pot, W. (2004) Means to improve social interaction in virtual learning environments. 1st Twente Caput \& Referaat Conference, Enschede, Netherlands.

Shaffer, D.; Squire, K.; Halverson, R.; Gee, J. (2004) Video games and the future of learning. University of Wisconsin-Madison and Academic Advanced Distributed Learning Co-Laboratory. Last access April 16, 2015, from http://www.academiccolab.org/resources/gappspaper1.pdf

TREE - (2007) Teaching and Research in Engineering in Europe Special, 20th Conference on Software Engineering Education \& Training, Dublin, Ireland.

VLEs4VET project, (2011). Reflecting on the implementation of the virtual learning environments in education across europe. Last access April 16, 2015, from http://www.adameurope.eu/prj/6441/prd/4/1/Reflecting\%20on\%20VLE\%20implementation.pdf

Woods, D. (1994) Problem based learning: How to get the most from PBL, McMaster University. 